\title{
Editorial
}

Welcome to 2005, our eighth year. I hope that we can all work together to make 2005 a landmark year for improving nutrition world-wide. I would like to take this opportunity to thank my editorial board and the many anonymous reviewers who have worked very hard to ensure that we deliver a high-quality journal. I would particularly like to thank Marilyn Tseng and Roger Hughes who have been outstanding servants of the journal. It is with great pleasure that I welcome Lenore Arab (great to have you back!) and Janet Cade onto the editorial team. I exhort you all to continue to help us in our efforts over the coming year - without your support we could not function. We all need our own work to be published, so we all rely on each other.

Our ambition remains to use the journal to improve nutrition around the world, by improving the links between research and practice, and by disseminating evidence of good practice, as well as evidence about the causes of nutrition health problems. I look forward to continued input to the journal from Geoffrey Cannon in a number of ways, most importantly through his column 'Out of the Box'. He has stimulated a lot of discussion and debate, and I continue to hold the view that this is a key function of our journal. I am grateful to his continued (and unpaid!) commitment to Public Health Nutrition.

I am always open to the views of our readers. If you want to challenge anything that is said in the journal, or to propose new ways of doing things that will make our work more effective, please write to us, and I will do all I can to give you a fair platform.

A major focus this year will be the IUNS Congress in Durban, which will draw world-wide attention to Africa (http://www.puk.ac.za/fakulteite/voeding/iuns/index. html). An ambition of the congress will be to strengthen capacity-building and links across Africa, particularly between younger nutritionists. The conference organisers are making strenuous efforts to facilitate the inclusion of young African nutritionists from around the world. It is clear, in my view, that the future of nutrition in Africa lies in supporting and enabling the brightest and the best young Africans to live and work in Africa. This raises many issues about salaries and job security for young nutritionists; why should we expect young African people to work for low wages in unstable economic environments - while at the same time many international agencies seek these same young people to work in exciting well-paid jobs overseas? These and many more issues will be debated at the congress. A new graduate student-led organisation has been formed (African Nutrition Graduate Students Network (AGSNet); http:// www.unu.edu/capacitybuilding/foodnutrition/ags-net/) and will hold its first meeting during the Durban congress.

In this issue, I highlight two UNICEF-led studies by Aguayo and colleagues ${ }^{1,2}$ that explore factors affecting the effectiveness of supplementation programmes in Africa.

The first study set out to estimate the potential impact on child survival of policies and programmes aimed at controlling vitamin A deficiency (VAD) in Mozambique ${ }^{1}$. Serum retinol was analysed in blood samples collected from a nationally representative sample of 6-59-monthold children using a two-stage cluster sampling method. Just over $70 \%$ of children were considered as vitamin-Adeficient based on a serum retinol concentration below $0.70 \mu \mathrm{moll}^{-1}$. In 2000/01, vitamin A supplements (VAS) were distributed at Mother and Child Health $(\mathrm{MCH})$ Days, and achieved 79\% and 91\% coverage in 2000 and 2001, respectively. In 2002, VAS was integrated into routine child health services, with a combination of fixed and mobile health posts. This change in mode of delivery was made because the $\mathrm{MCH}$ approach was too expensive in terms of human and financial resources. Coverage dropped from $91 \%$ in 2001 to $44 \%$ in 2003 . For VAS to be effective it must reach the target population at the appropriate time, which is at least every 6 months. The authors explored the potential for opportunistic contacts with children to increase the uptake of VAS; these included contacts with children either when they attend clinics when they are ill, or through vaccination campaigns and emergency response activities. The other issues they highlighted that reduced uptake were poor staff skills and an apparent lack of community demand. Priorities were therefore how to strengthen health workers' training, supervision and monitoring skills; and how to increase community demand for VAS of children. The authors argue that VAD control in children has the promise to be among the most cost-effective/high-impact child survival interventions in Mozambique.

In the second study, Aguayo et $a l^{2}{ }^{2}$ studied 70 pregnant Malian women aged between 18 and 40 years living in two health districts near the capital Bamako. Women in one centre ( 35 in each) were given iron plus folate and women in the other, a multiple micronutrient supplement. At the beginning of their second trimester women were given 90 tablets (a 3-month supply) with instructions as to how to use them. They were given a second and third sachet, each containing 90 tablets, 3 and 6 months later. Adherence and 
acceptability were good in both centres. The authors concluded that reliable supply, coupled with relevant and easily understandable information and counselling are crucial to successful supplementation programmes.

These two relatively small effectiveness studies highlight the importance of considering those factors that affect the implementation of programmes. The work highlights the importance of the link between the evidence base for what should work and why, with the evidence for what really works and why (or why not).

Supplementation is an important strategy to improve micronutrient status, and it is essential that this be made as effective as possible. We need to ensure that we address the underlying reasons why populations need to be supplemented; ideally people should have access (physical and economic) to the range of foods required to meet their needs. The challenge is to meet the immediate needs of addressing acute malnutrition, while addressing longterm strategies that promote better nutrition and health, particularly in the most vulnerable.

\section{Barrie Margetts}

Editor-in-Chief

\section{References}

1 Aguayo VM, Kahn S, Ismael C, Meershoek S. Vitamin A deficiency and child mortality in Mozambique. Public Health Nutrition 2005; 8(1): 29-31.

2 Aguayo VM, Koné D, Diallo B, Traoré D, Signé P, Baker SK. Acceptability of multiple micronutrient supplements by pregnant and lactating women in Mali. Public Health Nutrition 2005; 8(1): 33-7. 